\title{
OS GÊNEROS DISCURSIVOS NO SAEB E NA PROVA BRASIL DE 2007
}

PATRICIA ANDRÉA DE ARAÚJO QUEIROZ

\section{RESUMO}

Objetivou-se neste trabalho mapear os gêneros discursivos que constituíram o teste do 5a ano do Saeb e da Prova Brasil, de 2007, para analisar se o privilégio de determinados gêneros discursivos em detrimento de outros pode contribuir para a reprodução e manutenção de relações assimétricas de poder. Assim, para tratar dos conceitos de gênero discursivo e análise do discurso crítica, postulados básicos que orientam este trabalho, foram utilizadas as reflexões de Bakhtin, Marcuschi, Fairclough, Resende e Ramalho e Thompson. Para a coleta e análise dos dados, foi adotada a abordagem qualitativa recorrendo-se à análise documental. Os resultados da pesquisa mostraram que os gêneros mais recorrentes foram o conto e a história em quadrinhos, que pertencem a um mesmo domínio discursivo, o ficcional. Desta forma, ao priorizar alguns gêneros essa avaliação pode contribuir para que concepções hegemônicas sejam reproduzidas e mantidas, à medida que legitima determinados gêneros e, consequentemente, os discursos produzidos por eles. 


\section{RESUMEN}

Este trabajo tuvo por objetivo mapear los géneros discursivos que integraron la prueba de 5a año del Saeb y de la Prova Brasil 2007, para analizar si el privilegio dado a determinados géneros discursivos en detrimento de otros, puede contribuir a la reproducción y mantenimiento de relaciones asimétricas de poder. Así, para tratar los conceptos de género discursivo y análisis crítico del discurso, postulados teóricos que orientam este trabajo -, fueron utilizadas las reflecciones de Bakhtin, Marcuschi, Fairclough, Resende e Ramalho e Thompson. Para a compilación y análisis de los dados, fue adoptado el abordaje qualitativa usando también la análisis documental. Los resultados de la búsqueda revelaron que los géneros más recorrientes en la edición de 2007 fueron el cuento y los tebeos que pertenencian a un mismo dominio discursivo, la ficción. De esta manera, al elegir algunos géneros esa evaluación puede contribuir para que concepciones hegemónicas sean reproduzidas y mantenidas, a la medida que legitima determinados géneros $y$, consecuentemente, los discursos produzidos por ellos.

PALABRAS CLAVE SAEB • PROVA BRASIL • GÉNERO DISCURSIVO • EVALUACIÓN DE LA EDUCACIÓN BÁSICA.

\section{ABSTRACT}

The aim of this paper is to map the discursive genres that constituted the 5th grade 2007 tests from Saeb and Prova Brasil (Brazilian Test), in order to analyze if the privileged use of some discursive genres over others contributed to the reproduction and the maintenance of asymmetrical power relations. So as to deal with the concepts of discourse genre and critical discourse analysis, the bases that guide this work, we use the reflections by Bakhtin, Marcuschi, Fairclough, Resende and Ramalho and Thompson. To compile and analyze the data, we opted for a qualitative approach, using a documental analysis too. The results showed that the most recurrent genres in the 2007 edition were short stories and cartoons, which belong to the same discursive domain, fiction. Thus, by giving priority to some genres, this evaluation can contribute to maintain and to reproduce hegemonic conceptions, as it legitimates some genres and, consequently, the discourses produced by them. 


\section{INTRODUÇÃO}

1 Para uma análise mais detalhada sobre os conceitos de tempo e de espaço na modernidade, cf. Giddens (2002).

A industrialização e a expansão do capitalismo alterou a noção de tempo e de espaço, ${ }^{1}$ que em situações pré-modernas se conectavam através da situacionalidade do lugar. Isso acarretou mudanças nas instituições sociais, fazendo com que algumas delas desaparecessem e outras surgissem. A política de globalização da economia e da cultura alterou o consumo e os costumes, além de ter modificado as práticas discursivas e de produção escrita. Segundo Giddens (2002, p. 23), “a organização social moderna supõe a coordenação precisa das ações de seres humanos fisicamente distantes”.

A globalização e os avanços tecnológicos vêm mudando as formas de agir, pensar e ver o mundo. Hábitos e costumes de outros povos estão se incorporando aos nossos em uma rapidez, amplitude e profundidade jamais vivenciado por nenhum sistema social anterior, modificando nosso sistema de relações, constituindo novas identidades. Nessa nova configuração social, a leitura e a escrita, enquanto manifestação formal da comunicação, tornaram-se mais do que uma tecnologia. Para Marcuschi (2007, p. 16), a escrita 
[...] se tornou um bem social indispensável para enfrentar o dia a dia, seja nos centros urbanos ou zona rural, pode ser vista como essencial à própria sobrevivência no mundo moderno.

De acordo com Giddens (2002, p. 29), "O desenvolvimento e a expansão das instituições modernas estão diretamente envolvidos com o imenso aumento na mediação da experiência que as formas de comunicação propiciaram”. A partir desta ideia, a escrita e a leitura podem ser entendidas como ferramentas que possibilitam autonomia, ampliação dos horizontes, possibilidade de o indivíduo incorporar novos conhecimentos, modificar comportamentos e posicionamento dentro do grupo social no qual está inserido.

Neste contexto, a questão da qualidade educacional tem assumido lugar de destaque, principalmente no que diz respeito à competência leitora dos alunos que ingressam no sistema educacional brasileiro. Desde 1990, o Instituto Nacional de Estudos e Pesquisas Educacionais Anísio Teixeira (Inep), autarquia vinculada ao Ministério da Educação (MEC), vem aplicando testes de Língua Portuguesa e Matemática, para alunos do $5^{\circ}$ e $9^{\circ}$ ano do ensino fundamental e $3^{\mathrm{a}}$ série do ensino médio, para medir os níveis de proficiência dos estudantes da educação básica nessas disciplinas.

Em Língua Portuguesa, especificamente, os testes são compostos de diversos gêneros discursivos que circulam tanto no contexto da escola quanto no dia a dia dos alunos.

Os Parâmetros Curriculares Nacionais (PCN), desde que foram instituídos, há mais de três décadas, orientam o professor a trabalhar com diferentes gêneros discursivos de circulação social, para que o aluno tenha subsídios que garantam a ele efetiva participação na sociedade. Citando os pressupostos bakhtinianos, ${ }^{2}$ os PCN fazem referência à linguagem como forma de ação interindividual orientada por uma finalidade especifica "um processo de interlocução que se realiza nas práticas sociais existentes, nos diferentes grupos de uma sociedade, nos distintos momentos da sua história" (BRASIL, 1997, p. 23-24).

Sendo assim, entende-se que o discurso se realiza à medida que existe uma necessidade social de utilização, e se materializa em forma de um determinado gênero:
2 Cf. Bakhtin (2003, p 261-262): "O emprego da língua efetua-se em forma de enunciados (orais e escritos) concretos e únicos, proferidos pelos integrantes desse ou daquele campo da atividade humana. Esses enunciados refletem as condições especificas e as finalidades de cada referido campo não só por seu conteúdo (temático) e pelo estilo da linguagem, ou seja, pela seleção dos recursos lexicais, fraseológicos e gramaticais da língua mas, acima de tudo, por sua construção composicional. Todos esses três elementos estão indissoluvelmente ligados no todo do enunciado e são igualmente determinados pela especificidade de um determinado campo da comunicação. Cada enunciado particular é individual, mas cada campo de utilização da língua elabora seus tipos relativamente estáveis de enunciados, os quais denominamos gêneros do discurso". 
Todo texto se organiza dentro de um determinado gênero. Os vários gêneros existentes, por sua vez, constituem formas relativamente estáveis de enunciados, disponíveis na cultura, caracterizados por três elementos: conteúdo temático, estilo e construção composicional. Os gêneros são determinados historicamente. As intenções comunicativas, como parte das condições de produção dos discursos, geram usos sociais que determinam os gêneros que darão forma aos textos. (BRASIL, 1997, p. 26)

Considerando as ideias expostas sobre discurso, neste trabalho, objetivamos mapear os gêneros discursivos que constituíram o teste de Língua Portuguesa do $5^{\circ}$ ano do Sistema de Avaliação da Educação Básica (Saeb)/Prova Brasil 2007 para analisarmos se ao se privilegiar determinados gêneros em detrimentos de outros nestas avaliações pode-se contribuir para a reprodução e manutenção de relações assimétricas de poder, tendo em vista que ao investigarmos os gêneros discursivos, conhecemos a interação social em seus diversos âmbitos.

Tal afirmação é embasada por Bakhtin (2003, p. 266), que declara que

Em cada campo existem e são empregados gêneros que correspondem às condições especificas de dado campo; e a esses gêneros que correspondem determinados estilos. Uma determinada função (científica, técnica, publicística, oficial, cotidiana) e, determinadas condições de comunicação discursiva, específicas de cada campo, geram determinados gêneros, isto é, determinados tipos de enunciados estilísticos, temáticos e composicionais relativamente estáveis.

Para subsidiar tais reflexões traçaremos o percurso do Saeb desde que foi instituído, em 1990. Em seguida, apresentaremos a teoria de gênero do discurso na perspectiva da Análise do Discurso Crítica (ADC) e, por último, traremos algumas considerações a respeito da seleção dos gêneros discursivos que compuseram o testes de Língua Portuguesa do $5^{\circ}$ ano, edição de 2007 do Saeb/Prova Brasil, tendo por base a ADC. 


\section{SISTEMA NACIONAL DE AVALIAÇÃO DA EDUCAÇÃO BÁSICA - SAEB: UM BREVE HISTÓRICO}

Nos últimos dez anos, a questão da equidade e qualidade educacional tem assumido lugar de destaque nas discussões sobre o desenvolvimento de políticas públicas, suscitando a necessidade de se avaliar todos os níveis de ensino para obtenção de informações sobre a realidade educacional no País. Os indicadores de desempenho educacional ${ }^{3}$ demonstram que a questão do acesso está praticamente resolvida, uma vez que quase a totalidade das crianças ingressa no sistema educacional. O problema ainda reside nas altas taxas de repetência, na elevada proporção de adolescentes que abandonam a escola sem concluir a educação básica e na baixa proficiência obtida pelos estudantes brasileiros nos exames diagnósticos padronizados.

A necessidade de se obter mais informações sobre a educação brasileira levou o governo a criar um sistema de avaliação da educação. Surgido em 1990, o Saeb foi instituído com o intuito de desenvolver e aprofundar as capacidades avaliativas do Ministério da Educação e suas secretarias por meio do desenvolvimento de equipes especializadas, com o intuído de: regionalizar o processo avaliativo; articular os diversos trabalhos que estavam sendo realizados na área de avaliação; discutir as propostas curriculares; e, por fim, disseminar na sociedade questões relativas a parâmetros de qualidade (INEP, 1992).

A primeira prova Saeb teve como base uma pesquisa realizada junto a uma amostra de professores, que identificou os conteúdos praticados em sala de aula, já que, na época, ainda não existia um currículo comum instituído nacionalmente. Os professores que informaram esses conteúdos também elaborarem os itens que compuseram a primeira avaliação, aplicada aos alunos das $1^{\mathrm{a}}, 3^{\mathrm{a}}, 5^{\mathrm{a}}$ e $7^{\mathrm{a}}$ séries $^{4}$ (INEP, 1992).

O segundo ciclo do Saeb aconteceu em 1993 e foi marcado pelo aprimoramento de seus instrumentos de avaliação. $\mathrm{O}$ Ministério de Educação (MEC) realizou uma ampla consulta às secretarias estaduais, com o intuito de conhecer as propostas curriculares vigentes, que então foram analisadas por um grupo de especialistas de diversas universidades e, na sequência, sintetizadas e submetidas a outro grupo de especialistas
3 Cf. Fernandes (2007,

p. 7): Para o pesquisador "Os indicadores de desempenho educacional utilizados para monitorar o sistema de ensino no País, são fundamentalmente, de duas ordens: a) indicadores de fluxo (promoção, repetência e evasão) e b) pontuações exames padronizados obtidas por estudantes ao final de determinada etapa do sistema de ensino (4a e 8ª séries do ensino fundamental e 3 은 ano do ensino médio)" que são coletados pelo Instituto Nacional de Estudos e Pesquisas Educacionais Anísio Teixeira (Inep).

4 Após a instituição do ensino fundamental de nove anos, por meio da Lei Federal n. 11.274 , de 6 de fevereiro de 2006, que teve prazo de implantação pelos sistemas até 2010, a nomenclatura passou de série escolar para ano. Sendo assim, as séries citadas correspondem, respectivamente, ao 2ㅇ, 4ㅇ, $6 \div$ e 8o anos na nomenclatura atual. 
5 Cf. Inep (1999, p. 5-6): “Uma escala é uma maneira de ordenar medidas de acordo com valores arbitrados. [...] A teoria estatística utilizada no Saeb permite a construção de uma escala para cada disciplina, que engloba as três séries avaliadas e ordena o desempenho dos alunos em um continuum (do nível mais baixo para o mais alto). Isto é possibilitado pela aplicação de itens comuns entre séries e a transformação (equalização) das escalas de cada disciplina entre as séries para a obtenção de uma escala comum a todas as séries". e professores da rede de ensino fundamental. Com base nessa análise, foram elaboradas as questões que fariam parte da prova (BRASIL, 1995).

No final de 1994, o Saeb foi institucionalizado como um processo nacional de avaliação, por meio da Portaria n. 1.795/94 e, a partir de então, deveria contribuir para: o desenvolvimento de uma cultura avaliativa que estimulasse a melhoria dos padrões de qualidade e o controle social dos seus resultados; a implementação e o desenvolvimento de processos permanentes de avaliação e articulação com as secretarias de educação; a mobilização de recursos humanos; o fornecimento, à sociedade, de informações sobre o desempenho dos sistemas educativos brasileiros.

A partir de 1995, o Saeb sofreu várias modificações, começando pelas séries avaliadas, que passaram a ser apenas os finais de ciclos, ou seja, as $4^{\mathrm{a}}$ e $8^{\mathrm{a}}$ séries do ensino fundamental. Foi incorporada, também, a avaliação dos alunos da $3^{\mathrm{a}}$ série do ensino médio, e a abrangência da prova foi ampliada com a incursão das escolas privadas (INEP, 1998).

Nesse mesmo período foi implementada uma nova metodologia estatística que possibilitou a comparação entre anos e séries. Outra novidade foi a incorporação de temas socioeconômicos nos questionários contextuais aplicados aos alunos, professores e diretores escolares (INEP, 1998).

Em 1997, o Saeb inovou apresentando uma escala única de proficiência ${ }^{5}$ para cada disciplina avaliada, o que possibilitou a comparação com os resultados de 1995 e das avaliações posteriores.

Em 2001, considerando a nova Lei de Diretrizes e Bases da Educação Nacional (LDBEN), a disseminação dos Parâmetros Curriculares Nacionais (PCN) por todo País e a necessidade de se adaptar às exigências que a dinâmica de um mundo em permanente mudança impõe, as Matrizes de Referência do Saeb foram atualizadas (INEP, 2002).

O Inep realizou uma consulta às 12 unidades da Federação, por meio da qual se solicitava às equipes de ensino e aos professores regentes de turma de $4^{\mathrm{a}}$ e $8^{\mathrm{a}}$ série do ensino fundamental e do $3^{\circ}$ ano do ensino médio (cerca de 500 professores, abrangendo as cinco regiões do País) que verificassem a compatibilidade entre as matrizes vigentes e o currículo proposto pelos sistemas 
estaduais para as disciplinas de Língua Portuguesa e Matemática. Após essa ampla consulta, o Inep, juntamente com grupos de especialistas das duas áreas, revisaram e atualizaram as matrizes de referência vigentes até agora (INEP, 2002).

Em 2005, o Saeb sofreu novas modificações transformando-se em um sistema composto por dois processos de avaliação regulamentados pela portaria MEC n. 931/05: a Avaliação Nacional da Educação Básica (Aneb), que manteve a mesma característica e objetivos do Saeb aplicado até 2003; e a Avaliação Nacional do Rendimento Escolar (Anresc), mais conhecida como Prova Brasil, destinada a avaliar as escolas públicas do ensino fundamental.

A Prova Brasil vem sendo realizada em todas as escolas públicas com mais de 20 alunos matriculados nos $5^{\circ}$ e $9^{\circ}$ anos do ensino fundamental, que estejam localizadas na zona urbana. A prova avalia habilidades relacionadas a duas áreas do conhecimento: Língua Portuguesa, com ênfase em leitura, e Matemática, com ênfase na resolução de problemas.

Na aplicação de 2007 a amostra do Saeb passou a ser retirada do universo de alunos que fizeram a Prova Brasil. Essa medida foi importante para que os alunos que participam das duas avaliações pudessem realizar apenas uma prova. Além disso, foi criado o Índice de Desenvolvimento da Educação Básica (Ideb), que é composto pela pontuação média obtida em exames padronizados (Prova Brasil) por estudantes ao final de determinada etapa da educação básica e pela taxa média de aprovação dos estudantes da correspondente etapa de ensino (FERNANDES, 2007).

Em 2009, a Prova Brasil passou a contemplar também as escolas rurais com mais de 20 alunos por turma.

\subsection{O ENSINO DE LÍNGUA PORTUGUESA: \\ MUDANÇAS E PERSPECTIVAS}

Desde o início da década de 1980, o ensino vem passando por grandes transformações e reformulações em sua orientação metodológica e na redefinição dos seus objetivos. Foram várias as iniciativas tomadas, dentre elas destacam-se: a nova Lei de Diretrizes e Bases da Educação Nacional n. 9.394, de 20 de dezembro de 1996, que estabeleceu as diretrizes da educação nacional; a Resolução CNE/CP n. 01, de 18 de fevereiro de 2002, que instituiu diretrizes curriculares nacionais para a formação de professores da educação básica; e os Parâmetros 
Curriculares Nacionais (PCN) que passaram a orientar a qualidade do ensino no País.

No campo teórico-metodológico, o ensino da Língua Portuguesa também vem se modificando. Novas perspectivas teóricas submeteram o ensino da língua materna a críticas, bem como propuseram novos paradigmas didáticos (SOARES, 2008, p. 100). Segundo Rios (2010, p. 79), um dos conceitos que vem adquirindo projeção nos últimos anos é o de letramento, que como processo ocorrente na vida social, "compreende tudo que um indivíduo tenha feito de leitura e escrita em sua vida".

A finalidade do ensino de Língua Portuguesa tal como passou a ser tratada nas propostas curriculares orientam o professor a criar situações para que o aluno possa ampliar seu domínio discursivo nas diversas situações comunicativas e se torne um usuário competente da língua, bem como crítico, reflexivo e independente, possibilitando que ele seja plenamente inserido no mundo letrado e tenha ampliadas as possibilidades de efetiva participação social no exercício da cidadania (INEP, 2002, p. 17).

Nesse sentido, o texto passou a ser entendido como unidade comunicativa significativa por excelência e o estudo das estruturas linguísticas foi remodelado. Assim, o domínio da norma padrão não é mais o único objetivo e deve aliar-se à busca consciente de comportamentos compatíveis com as diversas situações de usos linguísticos, privilegiando o uso social da língua nas suas mais diversas manifestações. A respeito disso, Soares $(2009$, p. 72$)$ afirma que letramento, na perspectiva social,

[...] é o que as pessoas fazem com as habilidades de lei-

tura e escrita, em um contexto específico, e como essas habilidades se relacionam com as necessidades, valores e práticas sociais.

Desse modo, a escola tem o papel de agir como mediadora e organizadora de atividades que permitam aos alunos usarem a língua, tanto na modalidade oral quanto na escrita, em diferentes situações comunicativas, levando-os a posicionarem-se criticamente diante de tudo que ouvem, leem e escrevem, a formularem perguntas e articularem respostas significativas e adequadas às diferentes situações, percebendo finalidades e intenções explícitas e implícitas. 
É importante ressaltar a relevância do teor discursivo no ensino da língua. Tal perspectiva rompe com a tradição conteudística, de abordagens descontextualizadas e, assim, favorece o desenvolvimento de múltiplas capacidades comunicativas de que o sujeito deve dispor para responder às exigências de sua condição de ser social e participativo.

\subsection{O PROCESSO DE CONSTRUÇÃO E ESTRUTURAÇÃO}

DA PROVA DE LÍNGUA PORTUGUESA DO 5 ANO DO

\section{SAEB/PROVA BRASIL 2007}

Os itens que compõem a avaliação do Saeb/Prova Brasil são construídos com base em uma Matriz de Referência. Em Língua Portuguesa a Matriz foi estruturada tendo como foco a leitura, que abarca a competência do aluno para apreender o texto como construção de conhecimentos em diferentes níveis de compreensão, análise e interpretação. Os objetos de conhecimento ou conteúdos constituem instrumentos de acesso às competências linguísticas que o aluno/leitor demonstra por meio de um conjunto de habilidades específicas.

Além de reunir saberes significativos para alunos nas três etapas da educação básica, no $5^{\circ}$ e $9^{\circ}$ anos do ensino fundamental e $3^{\mathrm{a}}$ série do ensino médio, a referida Matriz privilegia conhecimentos linguísticos operacionais - ações que se fazem com e sobre a linguagem - e também leva em consideração as implicações culturais decorrentes do uso social da língua em uma sociedade complexa em que os conhecimentos constituídos pelo sujeito em situações escolares e extraescolares articulam-se ao grau de letramento dele e decorrem do grau de letramento da comunidade da qual ele faz parte.

Estruturalmente, a Matriz de Referência de Língua Portuguesa (Cf. Quadro 1) do Saeb/Prova Brasil se divide em duas dimensões: uma denominada "Objeto do conhecimento", em que são listados seis tópicos; e outra denominada "Competência", na qual os descritores trazem as habilidades a serem avaliadas em cada tópico. Para o $5^{\circ}$ ano do ensino fundamental são contemplados 15 descritores; e para o $9^{\circ}$ ano e a $3^{\mathrm{a}}$ série do ensino médio são acrescentados mais 6 , totalizando 21 descritores .

Podem ser identificados nas matrizes descritores comuns às três etapas avaliadas, porém existe diferença no que diz respeito ao grau de complexidade com que esses descritores são 
tratados pelos avaliadores. Assim, um mesmo descritor pode dar origem a itens de níveis de complexidade distintos, tanto do ponto de vista do objeto analisado, o texto, quanto do ponto de vista da tarefa a ser realizada para o processamento da leitura (INEP, 2002, p. 22).

Os testes das avaliações Saeb/Prova Brasil são elaborados com base em uma técnica denominada Blocos Incompletos Balanceados (BIB), com distribuição em espiral das habilidades (Balanced Incomplete Block with spiraling design). Por meio dessa metodologia, podem ser aplicados 169 itens de diferentes habilidades da Matriz de Referência para cada ano e disciplina. Esses itens são divididos em 13 blocos com 13 deles em cada. Os blocos são agrupados de três em três, formando 26 cadernos diferentes. Dessa forma, é possível ampliar o escopo dos conteúdos avaliados ao mesmo tempo em que se reduz o número de questões que cada aluno responde (INEP, 2002, p. 31).

Para a análise dos dados, utiliza-se a Teoria de Resposta ao Item (TRI), que possibilita que o desempenho dos alunos seja comparado no decorrer dos anos e entre as séries avaliadas. Para que a comparação ao longo dos anos se realize, são mantidos alguns itens comuns, já aplicados em edições anteriores. E para garantir a comparabilidade entre as três séries avaliadas, aplicam-se blocos de $5^{\circ}$ ano no $9^{\circ}$ ano do ensino fundamental e blocos do $9^{\circ}$ ano na $3^{\mathrm{a}}$ série do ensino médio.

A TRI também permite a locação dos itens em uma escala de desempenho, possibilitando, assim, a verificação do nível médio de desempenho dos alunos nas disciplinas avaliadas (INEP, 2002, p. 31). 


\section{QUADRO 1 - Matriz de Referência de Língua Portuguesa do 5ª ano do Saeb/Prova Brasil}

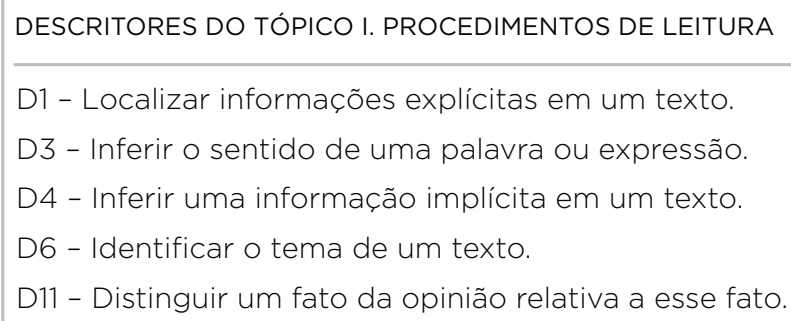

D5 - Interpretar texto com auxílio de material gráfico diverso (propagandas, quadrinhos, foto etc.).

D9 - Identificar a finalidade de textos de diferentes gêneros.

\section{DESCRITORES DO TÓPICO III. RELAÇÃO ENTRE TEXTOS}

D15 - Reconhecer diferentes formas de tratar uma informação na comparação de textos que tratam do mesmo tema, em função das condições em que ele foi produzido e daquelas em que será recebido.

DESCRITORES DO TÓPICO IV. COERÊNCIA E COESÃO NO PROCESSAMENTO DO TEXTO

D2 - Estabelecer relações entre partes de um texto, identificando repetições ou substituições que contribuem para a continuidade de um texto.

D7 - Identificar o conflito gerador do enredo e os elementos que constroem a narrativa.

D8 - Estabelecer relação causa/consequência entre partes e elementos do texto.

D12 - Estabelecer relações lógico-discursivas presentes no texto, marcadas por conjunções, advérbios etc.

DESCRITORES DO TÓPICO V. RELAÇÕES ENTRE RECURSOS EXPRESSIVOS E EFEITOS DE SENTIDO

D13 - Identificar efeitos de ironia ou humor em textos variados.

D14 - Identificar o efeito de sentido decorrente do uso da pontuação e de outras notações.

\section{DESCRITORES DO TÓPICO VI. VARIAÇÃO LINGUÍSTICA}

D10 - Identificar as marcas linguísticas que evidenciam o locutor e o interlocutor de um texto.

Fonte: Inep (2010). 


\section{OS GÊNEROS DISCURSIVOS NA PERSPECTIVA DA ANÁLISE DO DISCURSO CRÍTICA (ADC)}

Com base nos preceitos de Bakhtin sobre gêneros, as autoras Silva e Ramalho (2008, p. 21) afirmam que um dos conceitos centrais para se compreender os estudos sobre gêneros discursivos é o de "dialogismo". Para elas, toda interação social possui uma propriedade dialógica, e "mesmo os discursos aparentemente não dialógicos, como textos escritos, são internamente dialógicos e polifônicos".

ParaBakhtin(2003), a interaçãodialógica sóocorre porqueatende a uma necessidade discursiva específica e às "finalidades de cada referido campo" da comunicação, obedecendo a alguns critérios, taiscomo: "conteúdotemático" "estilodelinguagem"e "construção composicional”. Esses critérios estão indissoluvelmente ligados no todo doenunciado e são igualmente determinados pela especificidade de um determinado campo da comunicação.

Cada enunciado particular é individual, mas cada campo de utilização da língua elabora seus tipos relativamente estáveis de enunciados, os quais denominamos gêneros do discurso. (BAKHTIN, 2003, p. 261-262)

Diversos gêneros fazem parte das relações sociais e o indivíduo participa deles no momento em que atua diariamente nos meios sociais. Seja qual for o contexto, os gêneros discursivos perpassam todas as atividades sociais cotidianas e a todo tempo o indivíduo seleciona aqueles que considera mais adequados para atender a uma situação de interação.

Ao fazer essa escolha vários critérios são levados em consideração: o papel da linguagem na atividade específica, os temas relacionados, o tipo de atividade e as relações sociais envolvidas. Porém, a observância desses critérios não deve servir para enquadrar os gêneros discursivos em possibilidades únicas de utilização, pois Bakhtin (2003) enfatiza que os "gêneros são infinitamente ampliados, transmutados diferenciados, fundidos”, daí sua heterogeneidade característica.

Os gêneros discursivos também apresentam distintos níveis de abstração que podem ser classificados como "pré-gêneros", "gêneros desencaixados" e "gêneros situados".

Os gêneros primários/simples, na perspectiva de Bakhtin (2003, p. 263), 
[...] são mais abstratos, constituídos espontaneamente na vida cotidiana, em circunstâncias de comunicação menos complexas e participam na composição de diversos gêneros situados.

Marcuschi (2008, p. 154) designa os gêneros primários como tipos textuais, que são entendidos como "uma espécie de sequência teoricamente definida pela natureza linguística de sua composição (aspectos lexicais, sintáticos, tempos verbais, relações lógicas)". Dessa forma, os tipos textuais são caracterizados mais pela estrutura linguística do que pela materialização dos textos em um gênero e abrangem seis categorias conhecidas como narração, argumentação, exposição, descrição, injunção, diálogo. A mistura ou o hibridismo de tipos é denominada pelo pesquisador como "heterogeneidade tipológica" (MARCUSCHI, 2008, p.158).

Os gêneros secundários/complexos de Bakhtin (2003, p. 263) correspondem aos gêneros textuais de Marcuschi (2008, p. 155) e designam "realizações linguísticas" concretas, ou seja, são textos materializados em situações comunicativas recorrentes que

[...] apresentam padrões sociocomunicativos específicos característicos definidos por composições funcionais, objetivos enunciativos e estilos concretamente realizados na integração de forças históricas, sociais, institucionais e técnicas. (MARCUSCHI, 2008, p. 155).

Os gêneros desencaixados são realizações linguísticas materializadas como os gêneros secundários/complexos. Porém, transcendem "redes", “ordens" ou "domínios” discursivos, ou seja, são gêneros que transitam em várias ordens do discurso. Podemos citar como exemplo a entrevista e o depoimento, que transitam em diversas práticas, como jornalística, médica, acadêmica e publicitária (SILVA; RAMALHO, 2008, p. 29).

Considerando tais preceitos, a ADC contribui para o alcance do objetivo delineado para este estudo, a medida em que permite identificar na composição textual dos testes de Língua Portuguesa do $5^{\circ}$ ano do ensino fundamental elementos que apontam para relações assimétricas de poder, visto que a $\mathrm{ADC}$ se constitui como "ciência social crítica comprometida em oferecer suporte científico para questionamentos de problemas sociais relacionados a poder e justiça” (SILVA; RAMALHO, 2008, p. 2). 
6 Para maiores esclarecimentos sobre os modos de operação da ideologia, cf. Thompson (2002)
Nesta perspectiva, portanto, a linguagem é parte irredutível da vida social. Constitui-se socialmente na mesma medida em que tem "consequências e efeitos sociais, políticos, cognitivos, morais e materiais" (FAIRCLOUGH, 2003, p. 14).

Segundo Silva e Ramalho (2008, p. 23), “a ADC está preocupada com efeitos ideológicos que os textos possam ter sobre relações sociais, ações e interações, conhecimentos, crenças, atitudes, valores, identidades”, e oferece valiosa contribuição para o debate de questões ligadas ao racismo, à discriminação, à violência, à identidade, à manipulação institucional e à exclusão social (MAGALHÃES, 2005, p. 3).

Nessa perspectiva, Resende e Ramalho (2006, p. 50-51), embasadas por Thompson (2002), apresentam cinco modos gerais de operação da ideologia ${ }^{6}$ que servem para estabelecer e sustentar relações assimétricas de poder:

a. A legitimação que restabelece e sustenta relações de dominação pelo fato de serem apresentadas como justas e dignas de apoio e podem se basear em três estratégias de construção simbólica: a racionalização, a universalização e a narrativização;

b. A dissimulação que sustenta relações de poder por meio de sua negação ou ofuscação;

c. A unificação é o modus operandi da ideologia pelo qual relações de dominação podem ser estabelecidas ou sustentadas pela construção simbólica da unidade;

d. A fragmentação que sustenta relações de dominação por meio da segmentação de indivíduos e grupos que unidos, poderiam constituir obstáculos a manutenção do poder;

e. A retificação é o meio do qual uma situação transitória é representada como permanente, ocultando seu caráter sócio-histórico.

Essa abordagem da ideologia de Thompson, conjugada ao arcabouço teórico da $\mathrm{ADC}$ fornece ferramentas para se analisar, linguisticamente, construções discursivas revestidas de ideologias.

Chouliaraki e Fairclough (1999) reconhecem nos gêneros discursivos um "mecanismo articulatório que controla o que pode ser usado e em que ordem, incluindo configuração e ordenação de discursos". Para os autores, os gêneros discursivos regulam a prática do discurso, ou seja, controlam “o que”, “como”, e “onde” 
determinado discurso deve ser utilizado. Outro autor que também aborda essa questão é Marcuschi (2008, p. 161) quando afirma que "os gêneros são atividades discursivas socialmente estabilizadas que se prestam aos mais variados tipos de controle social e até mesmo ao exercício do poder", podendo servir como "forma de inserção, ação e controle social".

Levando em consideração essas conceituações, é possível inferir que os gêneros, além de controlar práticas discursivas, possibilitam e controlam práticas sociais como um todo e podem legitimar discursos ideológicos, maneiras particulares de representar ações "a partir de perspectivas posicionadas que suprimem contradições, antagonismos, dilemas, em favor de seus interesses e projetos de dominação" (CHOULIARAKI; FAIRCLOUGH, 1999).

\section{ANÁLISE DOS GÊNEROS DISCURSIVOS NO SAEB/PROVA BRASIL}

O objetivo nesta etapa do trabalho é apresentar uma análise geral dos gêneros discursivos que foram utilizados para a composição da avaliação do $5^{\circ}$ ano, de Língua Portuguesa do Saeb/Prova Brasil 2007. Serão expostos, também, dois itens que exemplificam os gêneros discursivos de maior recorrência nessa edição da avaliação.

Para a análise da tabela de distribuição dos gêneros que compuseram a prova, será utilizada a teoria de gêneros discursivos na perspectiva da $\mathrm{ADC}$, considerando que ela "está preocupada com efeitos ideológicos que os textos possam ter sobre relações sociais, ações e interações, conhecimentos, crenças, atitudes, valores, identidades" (SILVA; RAMALHO, 2008, p. 23).

No que concerne à análise dos dois itens que exemplificam os gêneros recorrentes na referida edição do Saeb/Prova Brasil, serão utilizados os modos gerais de operação da ideologia, visto que esses modos mostram "como o sentido pode servir para estabelecer e sustentar relações de dominação" (THOMPSON, 2002, p. 81). 


\subsection{ANÁLISE DOS GÊNEROS DISCURSIVOS QUE FORAM}

\section{UTILIZADOS NA AVALIAÇÃO DO 5 ANO, DE LÍNGUA}

PORTUGUESA, DO SAEB/PROVA BRASIL 2007

Na formulação de Bakhtin (2003, p. 266), os gêneros são empregados conforme condições específicas de um “dado campo, que correspondem a determinados estilos, função e condições de comunicação discursivas", o que significa que é o campo de comunicação discursiva que determina o gênero, o que Marcuschi (2008, p. 155) designa como “domínio discursivo”. Dentro desse domínio é possível identificar um conjunto de gêneros textuais específicos de determinada prática ou rotina comunicativa.

Marcuschi (2008, p. 194) apresenta um quadro de distribuição sistemática dos gêneros textuais por domínios discursivos. Ele explica que a relação apresentada não consiste em uma classificação, mas apenas em uma tentativa de demonstrar que os gêneros se distribuem na fala e na escrita dentro de um domínio discursivo.

Assim, com base nos conceitos teóricos expostos, bem como no quadro sugerido por Marcuschi, os gêneros utilizados na prova do $5^{\circ}$ ano de Língua Portuguesa do Saeb/Prova Brasil 2007 foram categorizados por domínios discursivos e expostos na Tabela 1.

É importante esclarecer que não há intenção de classificar os gêneros, pois, consoante Bakhtin (2003, p. 281), "não há razão para minimizar a extrema heterogeneidade dos gêneros do discurso". O que se pretende aqui é apenas mostrar como os gêneros discursivos foram contemplados e distribuídos nessa avaliação. 
TABELA 1 - Distribuição dos gêneros contemplados na avaliação do 5o ano do Saeb/Prova Brasil 2007 por domínio/campo discursivo

\begin{tabular}{|c|c|c|}
\hline DOMÍNIO DISCURSIVO & MODALIDADE ESCRITA & FREQUÊNCIA \\
\hline $\begin{array}{l}\text { Instrucional (científico, } \\
\text { acadêmico e educacional) }\end{array}$ & 4 tabelas; 5 verbetes; 1 jogo & 10 \\
\hline Jornalístico & $\begin{array}{l}1 \text { entrevista; } 1 \text { artigo de opinião; } \\
1 \text { reportagem; } 1 \text { comentário; } \\
1 \text { sinopse; } 1 \text { charge }\end{array}$ & 6 \\
\hline Religioso & - & O \\
\hline Saúde & 1 receita & 1 \\
\hline Comercial & - & 0 \\
\hline Industrial & - & 0 \\
\hline Jurídico & - & 0 \\
\hline Publicitário & 1 anúncio; 1 publicidade & 2 \\
\hline Lazer & $\begin{array}{l}9 \text { histórias em quadrinhos; } \\
3 \text { piadas; } 1 \text { trava-língua; } 1 \text { adivinha }\end{array}$ & 15 \\
\hline Interpessoal & 1 advertência; 1 provérbio & 2 \\
\hline Ficcional & $\begin{array}{l}7 \text { poemas; } 14 \text { contos; } \\
3 \text { mitos; } 4 \text { fábulas }\end{array}$ & 28 \\
\hline Militar & - & 0 \\
\hline Total & - & 64 \\
\hline
\end{tabular}

Fonte: Elaboração da autora.

Dos 12 domínios discursivos apresentados na Tabela 1, sugeridos por Marcuschi (2008, p. 194), apenas sete foram contemplados na edição de 2007, sendo que alguns domínios tiveram um ou dois gêneros representativos. Considerando o cotidiano do público-alvo para o qual essa avaliação foi aplicada, compreende-se que as práticas discursivas nos quais eles estão envolvidos são muito mais amplas dos que as contempladas no exame. A respeito disso, Bakhtin (2003, p. 266) menciona que "em cada campo existem e são empregados gêneros que correspondem às condições específicas de dado campo".

Os domínios discursivos que tiveram um número maior de gêneros contemplados foram o ficcional e o lazer, totalizando quase 70\%. Considerando-se que os gêneros contemplados não fazem parte das práticas discursivas rotineiras da parte majoritária 
dos alunos e que o contato com tais gêneros praticamente ocorre na escola, principalmente os relacionados ao domínio discursivo ficcional, parece que existe uma discrepância entre realidade discursiva vivenciada e a ensinada e mensurada pela escola.

Assim, os gêneros são definidos por eventos sociais concretos:

Quando se analisa um texto em termos de gênero, o objetivo é examinar como o texto figura na inter (ação) social e como contribui para ela em eventos sociais concretos. Gêneros específicos são definidos pelas práticas sociais a eles relacionadas e pelas maneiras como tais práticas são articuladas, de tal modo que mudanças articulatórias em práticas sociais incluem mudanças nas formas de ação e interação. (RESENDE; RAMALHO, 2006, p. 62)

É importante mencionar que os PCN (1997, p. 30) entendem ser papel da escola ensinar o aluno a recorrer aos gêneros para satisfazer as diversas necessidades pessoais, que podem ou não estar relacionadas às ações efetivas do cotidiano. Os documentos teórico-metodológicos que embasam o Saeb/Prova Brasil também orientam que "para ser competente no uso da língua é preciso saber interagir por meio de textos em qualquer situação de comunicação" (INEP, 2002, p. 18). Portanto, existe um discurso nos documentos oficiais que orientam a construção da avaliação de forma que ela contemple a diversidade de gêneros discursivos, porém, na prática, nem todos os gêneros estão efetivamente presentes.

Outro aspecto observado é que priorizar determinados gêneros discursivos na composição dos instrumentos de avaliação, em detrimento de outros, pode contribuir para a manutenção ou a reprodução de poder da classe dominante sobre a classe menos favorecida, já que esta possui pouco ou nenhum acesso aos bens culturais que compõem esses gêneros. Resende e Ramalho (2006, p. 46) afirmam que "textos como elementos de eventos sociais têm efeitos causais - acarretam mudanças em nosso conhecimento, em nossas crenças, atitudes, valores etc.”.

Fairclough (2001, p. 75), ao comentar a respeito da visão genealógica de Foucault, destaca que o poder é implícito nas práticas sociais cotidianas e só é tolerado porque mascara uma grande parte de si mesmo. 
Levando-se em conta que a estrutura composicional, o estilo e o meio social em que circulam os textos não fazem parte da prática cotidiana da maioria dos alunos que fez o Saeb/Prova Brasil 2007, pode-se concluir que esta edição da avaliação, ao privilegiar determinados gêneros, "estabelece restrições sociais ao acesso a certas práticas discursivas" (FAIRCLOUGH, 2001, p. 77), contribuindo, assim, para a reprodução de distribuição assimétrica de poder. Isso porque, quando determinado gênero não é dominado por um indivíduo, este se sente inibido a participar de atividades discursivas que façam parte das práticas sociais. Sobre isso Bakhtin (2003, p. 285) afirma que

Quanto melhor dominamos os gêneros tanto mais livremente os empregamos, tanto mais plena e nitidamente descobrimos neles a nossa individualidade (onde isso é possível e necessário), refletimos de modo mais flexível e sutil a situação singular da comunicação; em suma, realizamos de modo mais acabado o nosso livre projeto de discurso.

Outro aspecto relevante a ser observado é que a Matriz do Saeb/Prova Brasil possui apenas uma habilidade que aborda, de fato, aspectos relacionados ao texto literário. Entretanto, como se pode observar na tabela, a maior parte dos gêneros discursivos contemplados na edição em estudo são literários (conto, poema e história em quadrinhos). Assim, o Saeb pode estar reproduzindo uma prática já bastante criticada, tanto por pesquisadores que vêm acompanhando as mudanças no ensino da língua, como pelos próprios documentos oficiais que prescrevem que o texto literário e o ensino da literatura não devem ser tratados como "expediente para servir ao ensino das boas maneiras, dos hábitos de higiene, dos deveres do cidadão, dos tópicos gramaticais” (BRASIL, 1997, p. 37).

Ainda no que se refere à tabela de distribuição dos gêneros discursivos da edição de 2007 do Saeb/Prova Brasil, chama atenção a ocorrência do gênero histórias em quadrinhos. Dos nove textos utilizados, três são da Turma da Mônica, revista de circulação nacional, que reproduz muitas concepções ideológicas, dentre as quais destacam-se: incentivo à violência, representado principalmente pela personagem Mônica, que reage com agressividade aos insultos dos colegas; preconceito 
dos personagens Cebolinha e Cascão em relação ao estereótipo corporal de Mônica, que não se enquadra no padrão de beleza disseminado pela sociedade; depreciação das diferenças individuais, sofrida pelos personagens Cascão e Magali.

A partir dessa escolha textual para a representação do gênero história em quadrinhos, a avaliação pode estar legitimando vários discursos ideológicos. Todavia, é importante esclarecer que apesar de tal constatação se configurar como uma evidência de que os textos abarcam ideologias que podem estabelecer e sustentar relações de dominação, não se tem, nesta argumentação, a intenção de criticar o uso do gênero história em quadrinhos no Saeb/Prova Brasil. O objetivo dessa discussão é suscitar a reflexão de como os gêneros podem ser utilizados como veículo poderoso para manter e reproduzir ideologias de um determinado grupo sobre outro, e considerar que, muitas vezes, principalmente em uma avaliação da abrangência do Saeb/Prova Brasil, esse poder pode passar de forma despercebida.

\subsection{ANÁLISE DE DOIS ITENS QUE EXEMPLIFICAM \\ OS GÊNEROS DISCURSIVOS RECORRENTES \\ NA AVALIAÇÃO DO SAEB/PROVA BRASIL 2007}

\section{ANÁLISE 1}

ROBÔ

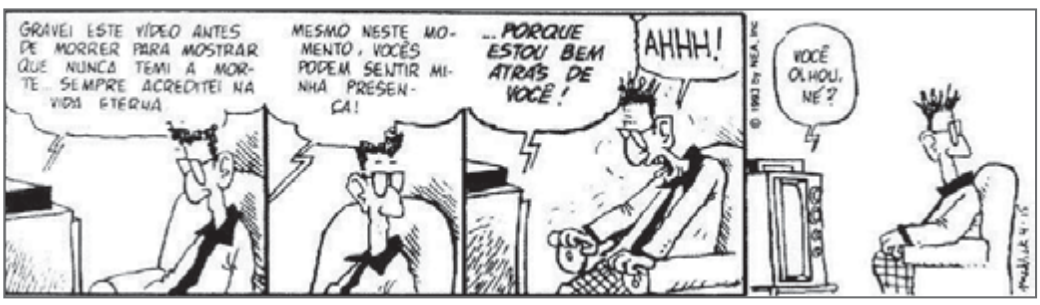

Fonte: Meddick (1993).

No $3^{\circ}$ quadrinho, a expressão do personagem e sua fala "AHHH!" indicam que ele ficou
(A) acanhado
(B) aterrorizado
(C) decepcionado
(D) estressado 


\begin{tabular}{|c|c|c|c|c|c|}
\hline \multicolumn{7}{|c|}{ PERCENTUAL DE RESPOSTAS ÀS ALTERNATIVAS } \\
\hline A & B & C & D & Em branco ou nulas \\
\hline $9 \%$ & $58 \%$ & $10 \%$ & $18 \%$ & $6 \%$ \\
\hline
\end{tabular}

Fonte: Aneb 2005, Português $4^{\mathrm{a}}$ série.

O gênero textual história em quadrinhos é um exemplo de que o significado do texto é construído pela linguagem verbal e não-verbal e que ambas se realizam em virtude de uma série de modos de representação e de comunicação que participam plenamente do discurso. As imagens, a linguagem informal em forma de diálogo, os assuntos e o tom de humor são responsáveis pela grande popularidade desses textos. Mas o que passa despercebido para a maioria dos leitores é que tais textos normalmente carregam mensagens preconceituosas e juízos de valor altamente ideológicos.

Uma das estratégias comumente utilizadas nesse gênero para legitimar relações de dominação é a narrativização, que consiste na narração de histórias do passado, conferindo ao presente um caráter determinista e aceitável, quando, de fato, essas histórias foram criadas para possibilitar "um sentido de pertença a uma comunidade e a uma história que transcende a experiência do conflito, da diferença e da divisão" (THOMPSON, 2002, p. 83).

Levando em consideração essas afirmações, observa-se que o texto em análise, ao apresentar o personagem Robô assistindo a um vídeo de alguém que já morreu e que o amedronta quando diz estar atrás dele, trata da vida após a morte de forma generalizada, como se todos tivessem medo, dessa forma legitimando o pensamento de um determinado grupo sobre outros.

Nas histórias corriqueiras e nas piadas que preenchem muito de nossas vidas cotidianas, estamos continuamente, engajados em recontar a maneira como o mundo se apresenta e em reforçar, através do humor que lucra às custas dos outros, a ordem aparente das coisas. (THOMPSON, 2002, p. 83)

Na modalidade imagética, o texto é altamente expressivo. $\mathrm{O}$ autor consegue, por meio da consonância entre a linguagem verbal e a não-verbal, transmitir toda expressividade 
de um comportamento humano frente a uma situação inesperada, nesse caso, o medo. É possível perceber o estado emocional do personagem, assim como as reações dele frente ao medo provocado pela fala do vídeo.

No entanto, é importante ressaltar que o medo, normalmente tratado como uma situação séria e de desconforto, é o principal causador de humor. Nesse caso, a estratégia utilizada para manutenção e reprodução do modo de reificação de operação da ideologia foi a da naturalização que, segundo Thompson (2002, p. 88), é uma formação simbólica de "um estado de coisas que é uma criação social e histórica que pode ser tratado como um acontecimento natural".

\section{ANÁLISE 2}

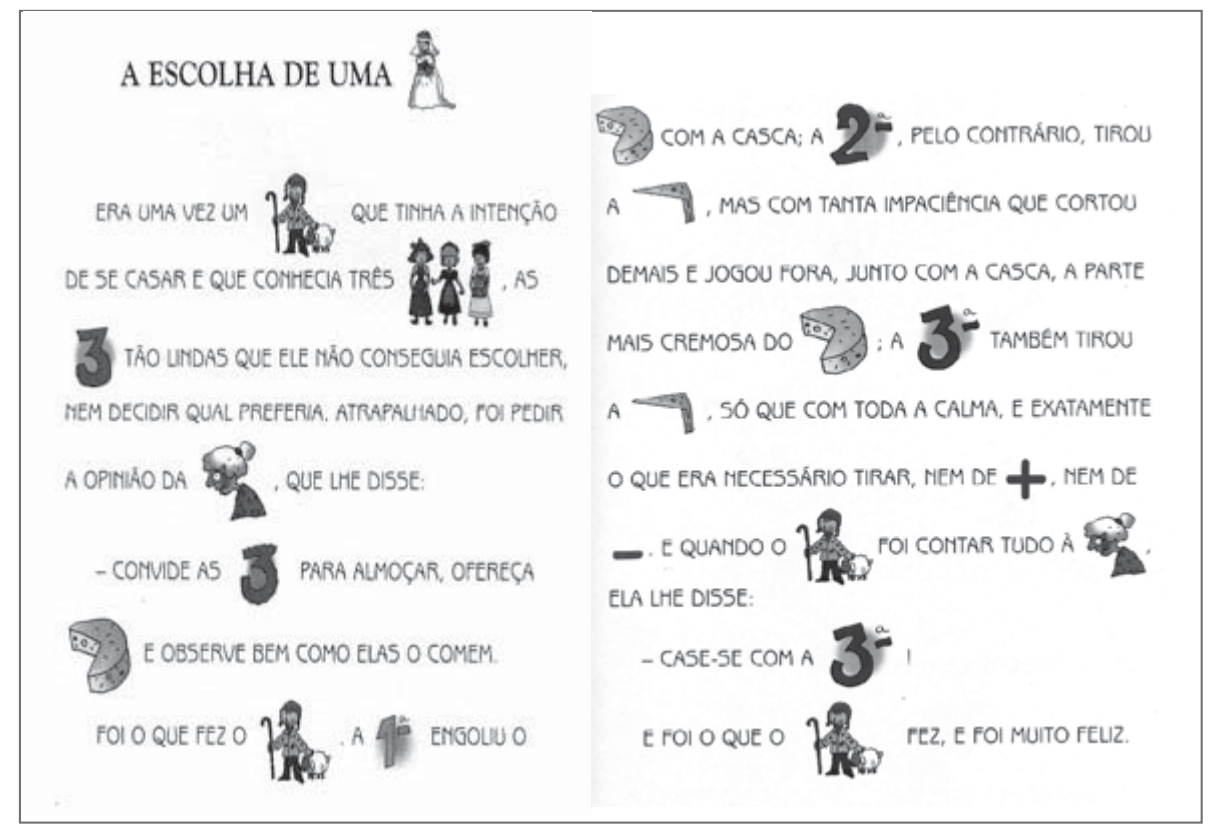

Fonte: Rimm (2001).

A terceira moça foi a escolhida pelo rapaz porque ela

(A) demonstrou que era cuidadosa e paciente.

(B) era mais rápida que as outras.

(C) provou que os últimos serão os primeiros.

(D) sabia como se comportar à mesa. 


\begin{tabular}{|c|c|c|c|c|}
\hline \multicolumn{7}{|c|}{ PERCENTUAL DE RESPOSTAS ÀS ALTERNATIVAS } \\
\hline A & B & C & D & Em branco ou nulas \\
\hline $59 \%$ & $9 \%$ & $5 \%$ & $21 \%$ & $6 \%$ \\
\hline
\end{tabular}

Fonte: Aneb 2005, Português $4^{a}$ série.

O gênero conto desperta bastante interesse no leitor pela capacidade que tem de proporcionar expectativas e emotividade, além de possuir uma unicidade dramática e ser uma narrativa pequena que pode ser lida em um período curto de tempo. Outra característica desse gênero é que ele seduz a partir do momento que retira elementos da realidade cotidiana ou do ficcionalismo e os transforma em episódios isolados.

O conto foi o gênero majoritariamente contemplado nessa edição do Saeb: foram 14 no total, mais 3 mitos e 4 fábulas, sendo que estes últimos são diferenciados do total por possuírem uma estrutura composicional semelhante ao conto.

Embora o conto seja bastante apreciado pelo estilo e estrutura composicional, ele também pode ser utilizado para estabelecer e sustentar relações de dominação, e uma das estratégias mais utilizadas para o alcance desse objetivo é a narrativização. Através dela, são contadas histórias das tradições passadas como se fossem imutáveis e aceitáveis. Um exemplo dessa prática são as histórias contadas pelas pessoas para exemplificar, sugerir ou julgar padrões de comportamento, já que

[...] histórias são contadas tanto pelas crônicas oficiais como pelas pessoas no curso de suas vidas cotidianas, servindo para justificar o exercício de poder por aqueles que o possuem. (THOMPSON, 2002, p. 83)

O texto utilizado para a análise 2 ilustra com clareza essa relação de legitimação quando estabelece critérios a serem observados para se escolher uma esposa. Quando o personagem recorre à mãe como uma pessoa que exerce autoridade e apela para costumes tradicionais, existe uma tentativa do autor em construir uma cadeia de raciocínio que procura defender, ou justificar, um conjunto de relações ou instituições sociais que estabelecem os paradigmas do que se convenciona como critérios corretos e dignos de apoio (THOMPSON, 2002, p. 82). 
Observa-se que o modus operandi da ideologia, bastante comum nesse gênero, é a reificação, que retrata uma situação transitória, histórica, como se essa situação fosse permanente e natural. "Processos são retratados como coisas, ou como acontecimentos de um tipo quase natural de tal modo que o seu caráter social e histórico é eclipsado" (THOMPSON, 2002, p. 87).

\section{CONCLUSÕES E PERSPECTIVAS}

O presente trabalho teve como objetivo inicial o mapeamento dos gêneros discursivos que constituíram a avaliação do $5^{\circ}$ ano do Saeb/Prova Brasil 2007 e a análise, por meio da perspectiva da Análise do Discurso Crítica, de alguns gêneros contemplados no exame, em detrimento de outros, que contribuíram para a reprodução e manutenção das relações assimétricas de poder.

A análise da avaliação do $5^{\circ}$ ano, edição Saeb/Prova Brasil 2007, mostrou que é necessário reconsiderar a composição textual dessa avaliação, no que tange aos gêneros contemplados. É preciso abarcar uma diversidade maior de gêneros para não apenas cumprir as orientações prescritas nos documentos oficiais, mas principalmente aproximar essa avaliação das práticas sociais vivenciadas pelos estudantes diariamente.

No entanto, é importante esclarecer que não se pode afirmar que todas as edições do Saeb/Prova Brasil incorreram no mesmo problema, pois para proceder a essa consideração seria necessário analisar as demais edições.

Quando alguns gêneros são priorizados em detrimento de outros, como foi apontado na análise da história em quadrinhos e do conto, pode-se afirmar, com base na teoria da ADC, que tais escolhas não são aleatórias, mas refletem concepções ideológicas de quem constrói esses instrumentos, mesmo que isso ocorra de forma inconsciente. Além disso, é preocupante o fato de uma avaliação de abrangência nacional, que define recursos e políticas públicas, conforme o desempenho apresentado pelos alunos, possuir tão poucos gêneros que, de fato, representem a prática social vivenciada no dia a dia.

Outro aspecto que deve ser repensado no desenvolvimento da prova é a utilização dos gêneros literários para avaliar habilidades relacionadas à análise textual. A sugestão é que para se 
aferir as habilidades relacionadas ao tópico IV da Matriz de Referência, que trata da coesão e coerência no processamento do texto, sejam contemplados outros gêneros, de preferência que encerrem textos curtos, para que não se incorra no equívoco de se utilizar o texto literário apenas como pretexto para aferir tópicos gramaticais, visto que,

[...] descontextualizada, tais práticas pouco ou nada contribuem para a formação de leitores capazes de reconhecer as sutilezas, as particularidades, os sentidos, a extensão e a profundidade das construções literárias. (BRASIL, 1997, p. 38)

Devido à abrangência do Saeb/Prova Brasil e sua repercussão no cenário educacional brasileiro, ao priorizar alguns gêneros essa avaliação pode contribuir para que concepções hegemônicas sejam reproduzidas e mantidas, à medida que legitima determinados gêneros e, consequentemente, os discursos produzidos por eles. A ADC, ao definir o discurso como prática social, corrobora essa análise, pois considera a seleção e distribuição dos gêneros discursivos nessa avaliação como um momento de prática social que possibilita o domínio de um grupo sobre os demais.

Por fim, a análise dos gêneros contemplados nesta edição do Saeb/Prova Brasil, traz uma reflexão que muitas vezes tem passado despercebida e que perpassa tanto pela qualidade dos instrumentos produzidos, quanto pelas mensagens ideológicas que são disseminadas e que têm contribuído para manter relações de poder de um grupo que têm acesso e manipula esses gêneros, conforme suas necessidades discursivas, sobre outro grupo que não domina ou não tem acesso a essas práticas.

\section{REFERÊNCIAS}

BAKHTIN, Mikhail. Os Gêneros do discurso. In: . Estética da criação verbal. 4. ed. Tradução de Paulo Bezerra. São Paulo: Martins Fontes, 2003 [1953].

BRASIL. Relatório do $2^{\circ}$ ciclo de aferição sistema nacional de avaliação da educação básica. Brasília: SEF/MEC, 1995. 
Parâmetros Curriculares Nacionais: língua portuguesa e ensino de primeira a quarta série. Brasília: MEC/SEF, 1997.

Portaria MEC n. 931 de 21 de março de 2005: Institui o Sistema de Avaliação da Educação Básica - Saeb. Diário Oficial da União, 22 mar. 2005.

CHOULIARAKI, Lilie; FAIRCLOUGH, Norman. Discourse in late modernity: rethinking critical discourse analysis. Edinbourg University, 1999.

FAIRCLOUGH, Norman. Michel Foucault e a análise de discurso. In: Discurso e mudança social. Tradução de Isabel Magalhães. Brasília: UnB, 2001.

El análisis crítico del discurso como método para la investigación en ciencias sociales. In: WODAK, R.; MEYER, M. (Comp.) Métodos de análisis crítico del discurso. Barcelona: Gedisa, 2003.

FERNANDES, Reynaldo. Índice de desenvolvimento da educação básica (Ideb). Brasília: Inep, 2007.

GIDDENS, Anthony. Modernidade e identidade. Tradução de Plínio Dentzien. Rio de Janeiro: Zahar, 2002.

INSTITUTO NACIONAL DE ESTUDOS E PESQUISAS EDUCACIONAIS ANÍSIO TEIXEIRA. Relatório do Sistema Nacional de Avaliação da Educação Básica - 1990. Brasília: Inep, 1992. Saeb/95: relatório final. Brasília: Inep, 1998.

Saeb 97: primeiros resultados. Maria Inês Gomes de Sá Pestana et al. Brasília: Inep, 1999.

. Saeb 2001: novas perspectivas. Brasília: Inep, 2002.

. Guia para elaboração e revisão de itens. Brasília: Inep, 2010.

MAGALHÃES, Isabel. Introdução à análise do discurso crítica. DELTA:

Documentação e Estudos em Linguística Teórica e Aplicada, São Paulo, v. 21, 2005.

MARCUSCHI, Luiz Antonio. Da fala para a escrita: atividades de retextualização. São Paulo: Cortez, 2007.

Produção textual, análises de gêneros e compreensão. São Paulo: Parábola, 2008.

MEDDICK, Jim. Robô. Folha de São Paulo, 27 abr. 1993.

RESENDE, Viviane de Melo; RAMALHO, Viviane. Análise de discurso crítica. São Paulo: Contexto, 2006.

RIMM. A escolha de uma esposa. In: MATOS, Magna Diniz; ASSUMPÇÃO, Solange Bonomo. Na trilha do texto: alfabetização: novo. São Paulo: Quinteto Editorial, 2001.

RIOS, Guilherme Veiga. Considerações sobre letramento, escolarização e avaliação educacional. In: Práticas socioculturais e discurso: debates transdisciplinares. Covilhan: LabCom, 2010.

SILVA, Denize Elena Garcia da; RAMALHO, Viviane. Reflexões para uma abordagem crítica dos gêneros discursivos. Revista Latinoamericana de Estudios del Discurso, v. 8, n. 1, p. 19-40, 2008. Disponível em: <http//www.portalaled. com/node/227>. Acesso em: 2 mar. 2010. 
SOARES, Magda. Alfabetização e letramento. 5. ed. São Paulo: Contexto, 2008.

. Letramento: um tema em três gêneros. 2. ed. Belo Horizonte:

Autêntica, 2009.

THOMPSON, John B. Ideologia e cultura moderna: teoria social crítica na era dos meios de comunicação de massa. 6. ed. Tradução de Pedrinho A. Guareschi. Petrópolis: Vozes, 2002.

\section{PATRICIA ANDRÉA DE ARAÚJO QUEIROZ}

Mestranda em Educação pela Universidade de Brasília (UnB).

Técnica em Assuntos Educacionais do Instituto Nacional

de Estudos e Pesquisas Educacionais Anísio Teixeira (Inep)

patriciaju09@gmail.com; patricia.pereira@inep.gov.br 